ORIGINAL RESEARCH

\title{
Wilderness Rescue and Border Enforcement Along the Arizona Mexico Border-The Border Patrol Search, Trauma and Rescue Unit
}

\author{
Samuel M. Keim, MD, MS; Frank Reiser, MD; Sheetal Shetty, BS; James Ranger-Moore, PhD \\ From the Department of Emergency Medicine, The University of Arizona College of Medicine, Tucson, AZ (Dr Keim); the Division of \\ Biostatistics and Epidemiology, Mel and Enid Zuckerman College of Public Health, The University of Arizona College of Medicine, Tucson, \\ AZ (Dr Reiser); and the Carondelet St. Joseph's Medical Center, Tucson, AZ (Ms Shetty and Dr Ranger-Moore).
}

\begin{abstract}
Objective.-To introduce and describe the US Border Patrol (USBP) Tucson Sector Border Patrol Search, Trauma and Rescue Unit (BORSTAR) and to analyze whether the frequency of its activities were associated with the amount of total border patrol law enforcement activities in the area.

Methods.-Descriptive and nonparametric analysis was conducted on data that were obtained on total USBP apprehensions of undocumented immigrants and BORSTAR activities for a consecutive 3-year period.

Results.-From October 2004 to September 2007 over 1 million apprehensions occurred within the Tucson Sector. During this time, a large number of search, rescue, and medical intervention events occurred. However, only a weak association was found between the frequency of apprehensions and BORSTAR activities.

Conclusions.-The BORSTAR unit of the Tucson Sector commonly encounters harsh conditions and provides search, rescue, and medical interventions to undocumented immigrants. The frequency of BORSTAR activities is not strongly associated with the volume of USBP law enforcement activities.

Key words: Tactical Emergency Medical Services, heat stroke, undocumented immigration, search and rescue
\end{abstract}

\section{Introduction}

The border of the United States is well defined but constitutes a unique and growing opportunity for search and rescue activity, specifically because of covert crossing attempts by undocumented immigrants. Most recently these attempts have largely occurred in the desert wilderness of Arizona. ${ }^{1}$ The Arizona-Mexico border region is mostly remote and rugged-which may partially explain why someone desiring a covert crossing would choose the area. Although difficult to accurately measure, the number of individuals who died while attempting to cross the Arizona-Mexico border appears to have increased sharply over the last 10 years. ${ }^{2-4}$ Illicit drug smugglers frequently choose routes through these areas as well. Planning emergency medical services to accom-

Corresponding author: Samuel M. Keim, MD, MS, PO Box 245057, Tucson, AZ 85724-5057 (e-mail: sam@aemrc.arizona.edu). pany law enforcement for this region is a tremendous challenge.

\section{Background}

The Border Patrol Search, Trauma and Rescue (BORSTAR) units were first created by the US Border Patrol (USBP) in 1998. ${ }^{5}$ Each Border Patrol sector in the country maintains a BORSTAR tactical emergency medical services (EMS) rescue unit. Each is composed of specially trained agents who perform law enforcement, search and rescue (SAR), and emergency medical response. All BORSTAR agents obtain tactical EMS training along with medical training ranging from basic Emergency Medical Technician to Paramedic certification with USBP training academies. The Tucson Sector BORSTAR unit Academy was also created in 1998 and graduated its first class of 30 members in 1999. Upon completion of the basic academy, the agents continue 
with training and quarterly competency to maintain and develop tactical EMS skills. Structured experiences include time in Tucson-area emergency departments and EMS units, navigational coursework, all-terrain vehicle and motorcycle operation, technical and swift-water rescue, communications, and canine training. The Tucson Sector BORSTAR unit's primary mission is to respond to distressed migrants and agents along the border. These are predominantly heat-stressed individuals encountered during the summer months. The unit is under the direction of BORSTAR agents with advanced training as well as board-certified emergency physicians.

Activations or calls for BORSTAR assistance are made by Tucson Sector Border Patrol central command dispatch. Calls from non-USBP agencies are routed through the central command dispatch. Calls for assistance include critical information that is used to determine quickly if the call will require SAR activation or a medical evaluation and possible intervention with SAR. Medical interventions are defined as administration of prehospital therapy (oxygen, intravenous fluid, medications, injury management, cooling or warming measures). Medical evaluations and interventions frequently occur after individuals are apprehended and when agents at the scene determine BORSTAR assistance is needed. Individuals who require evacuation are transported by USBP and non-USBP EMS ground and air ambulances to the nearest medical facilities. Medical evaluations and interventions also occur at detention facilities within the sector. BORSTAR agents complete an After Action Report for every incident in which they participate. The After Action Report contains details of the operation, including date, location, mechanism of notification, final disposition, number of agents and subjects, a description of the operation, equipment used, medical interventions, and other agencies responding. Information from the After Action Report is entered into a computer database at Tucson Sector Headquarters for BORSTAR (in Tucson, AZ).

A large number of undocumented border crossers are apprehended and temporarily detained by the USBP each year. The Tucson Sector of the USBP typically has the largest volume of apprehensions and marijuana seizures of all sectors in the country. The Tucson Sector comprises the majority of the State of Arizona, covering over 89000 square miles and including a total of 262 border miles. The Sector employs over 2900 agents working from 8 stations. As the precise number of undocumented border crossers is unknown, the published USBP apprehensions have become a surrogate for this volume. The goal of this study was to introduce this unique tactical EMS operation, provide descriptive data on its recent activities, and analyze whether any asso- ciation exists between the volume of apprehensions and the number of search and rescue events.

\section{Methods}

We conducted an analysis of 3 consecutive years of prospectively obtained BORSTAR program data. BORSTAR activity and overall apprehension data were obtained directly from the USBP Tucson Sector Public Affairs Office. As annual cycles are based upon the US government fiscal year that begins and ends on October 1, the start date for this study was October 1, 2004, and the end date was September 30, 2007. Data obtained included the number of search events, individuals rescued, number of individuals who required medical interventions, dead body recoveries, and documentation of US citizenship or other acceptable Customs and Border Protection documentation. These categories were not mutually exclusive. Search events were defined as those SAR attempts that resulted from specific requests. Rescues were defined as individuals who were sought and found after a SAR request was specifically made. Medical interventions were defined as administration of prehospital therapy, regardless of the nature of the contact with the individual (typical apprehension, SAR, or in temporary detention). The study received approval from the USBP and was reviewed by the Human Subjects Protection Program at The University of Arizona and was exempted from full committee review. Data were extracted and entered into an Excel database (Microsoft Office Excel 2003, Redmond, WA). Descriptive statistics were calculated, and the association between monthly total BORSTAR encounters and USBP apprehensions for the Tucson Sector was determined. Because of the presence of outliers in the scatterplot for encounters vs. apprehensions, a nonparametric Spearman correlation was used. Significance was set at a $P$-value of less than .05 .

\section{Results}

The Tucson Sector BORSTAR experienced 501 search events, 954 medical interventions, and 1667 rescues over the 3-year study time period evaluated. The BORSTAR group also performed 162 body recoveries over the course of the study period. The vast majority of these encounters involved undocumented immigrants suffering heat illness, while 4\% involved US citizens and $3 \%$ involved USBP agents. In the Tucson Sector during the same period, the USBP apprehended 1209392 undocumented immigrants. The number of Tucson Sector BORSTAR searches, rescues, and medical interventions compared to the apprehended undocumented immigrants 
Summary of Events and Apprehensions by Month

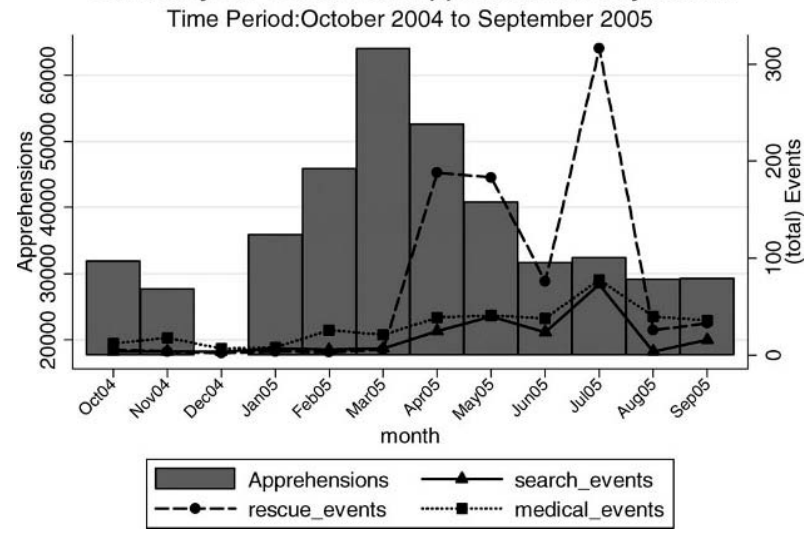

Figure 1. US Border Patrol apprehensions and Border Patrol Search, Trauma and Rescue Unit (BORSTAR) activity, 2005.

for the same months for each of the years is shown in Figures 1 through 3 .

Over the study period, a statistically significant but weak association was found between the total monthly number of USBP apprehensions and the total monthly number of search activations (Spearman's rho $=0.45, P$ $=.006)$ and medical interventions (Spearman's rho $=$ $0.476, P=.003)$. No statistical association was found between apprehensions and the total monthly number of rescues completed (Spearman's rho $=0.27, P=.11$ ).

\section{Discussion}

Unauthorized crossings along the Arizona-Mexico border and deaths associated with these crossings have been well publicized in the media and scientific literature. Not well documented is the presence and activity of the integrated tactical EMS system within the USBP. BORSTAR is a unique and very active search, rescue, and medical intervention unit that is similar in construction and operation to other tactical EMS operations. ${ }^{6}$

The Tucson Sector BORSTAR activities are likely different from other USBP teams secondary to the very large volume of border enforcement activities and the extreme wilderness environment in which the sector's agents serve. Daytime summer temperatures in this area frequently exceed $100^{\circ} \mathrm{F}$. This harsh climate necessitates training and equipment specific to the needs of the area and population crossing the border. Undocumented immigrants have likely chosen these remote deserts as crossing zones because of their distance from civilization and based on a perceived decrease in border enforcement. Unfortunately, this remoteness and their covert crossing behavior directly place these individuals at great risk from environmental hazards. Heat-related death is the leading cause of death in United States-

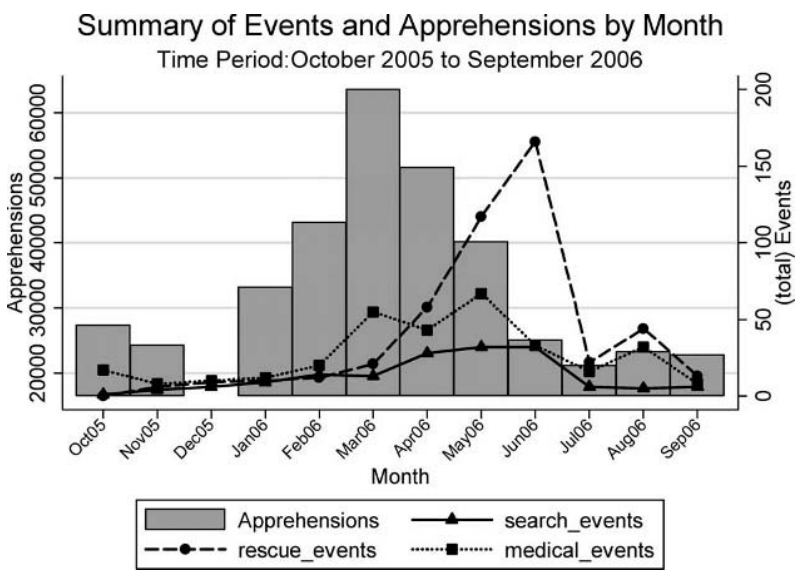

Figure 2. US Border Patrol Apprehensions and Border Patrol Search, Trauma and Rescue Unit (BORSTAR) activity, 2006.

Mexico border crossers, and the vast majority of these deaths occur in the Tucson Sector of the Arizona-Mexico border. This environment also places the USBP field agents at risk, and a small number of them have required BORSTAR rescues as well.

Apprehension statistics kept by USBP have commonly been used as a surrogate for the unknown volume of undocumented immigrants crossing the United StatesMexico border. Our analysis showed that there was a weak but statistically significant association between the volume of apprehensions and BORSTAR activities. This indicates that the risk of such activations occurring is not explained solely by the volume of immigrants. It is likely that a certain group of these individuals is placing themselves at substantially higher risk. Individual risk would be expected to be increased when specific disease processes are at highest risk (eg, summer heat waves, conditions that may discourage large numbers of potential crossers from making the attempt to begin with).

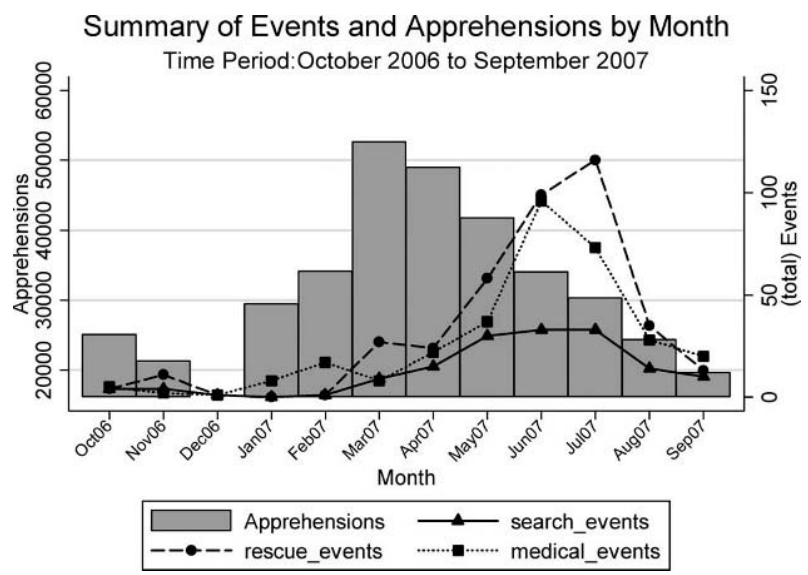

Figure 3. US Border Patrol Apprehensions and Border Patrol Search, Trauma and Rescue Unit (BORSTAR) activity, 2007. 
Although we did not statistically analyze for this potential association, visual inspection of Figures 1, 2, and 3 shows an increase in all 3 BORSTAR activities in late spring and summer months. This is consistent with other studies on the same population. ${ }^{2-4}$

This study has several limitations. Most importantly, the assumption that the volume of apprehensions is an accurate reflection of actual border-crosser volume is clearly filled with uncertainty. Changes in law enforcement strategy and border-crosser behavior are clearly important potential confounders. The database utilized comprised program data that were not originally structured for rigorous statistical analysis, and errors in coding and entry are possible. It is hoped that future work will include construction of a detailed event report database.

\section{Conclusion}

The Tucson Sector BORSTAR unit is a busy tactical EMS operation. This study found only a weak association between the estimated volume of the population served and the incidence of search and rescue activities. Apprehension volume is likely insufficient for determining future deployment strategies.

\section{References}

1. Customs and Border Protection. Border Security: The Role of the U.S. Border Patrol. Congressional Report. May 10, 2005; Available at: http://www.cbp.gov/xp/cgov/newsroom/ commissioner/speeches_statements/archives/2005/03302005_ press_conf_abci.xml. Accessed August 29, 2008.

2. Keim SM, Mays MZ, Parks B, Pytlak E, Harris RM, Kent MA. Estimating the incidence of heat-related deaths among immigrants in Pima County, Arizona. J Immigr Minor Health. 2006;8:185-191.

3. Keim SM, Mays MZ, Parks B, Pytlak E, Harris RM, Kent MA. Heat fatalities in Pima County, Arizona. Health Place. 2007;13:288-292.

4. Sapkota S, Kohl HW III, Gilchrist J, et al. Unauthorized border crossings and migrant deaths: Arizona, New Mexico, and El Paso, Texas, 2002-2003. Am J Public Health. 2006; 96:1282-1287.

5. Customs and Border Protection. Border Patrol Search, Trauma and Rescue (BORSTAR). Available at: http://www. cbp.gov/xp/cgov/border_security/border_patrol/special_oper/ borstar/borstar.xml. Accessed August 29, 2008.

6. Heiskell LE, Carmona RH. Tactical emergency medical services: an emerging subspecialty of emergency medicine. Ann Emerg Med. 1994;23:778-785. 